Title: A good fit: the contribution of action learning to supervision practice

Author: Frances Patterson

Senior Teaching Fellow in the Social Work (Post-Qualifying provision) team at University of Stirling. Teaching interests are focused on leadership, management and supervision in social services.

Frances Patterson, Faculty of Social Sciences, University of Stirling, Stirling, FK9 4LA. Tel: 01786 466305; E-mail: m.f.patterson@stir.ac.uk

Acknowledgments: The ideas presented in the article are developed from teaching on post-qualifying courses for managers and supervisors in Scotland's social services. Thanks are due to course participants and to Robin Burgess who first introduced me to action learning in 2001.

This article has been accepted for publication in Social Work Education and is available at: $\underline{\text { http://dx.doi.org/10.1080/02615479.2016.1246523 }}$ 


\begin{abstract}
This paper discusses the value of action learning for social work supervisors. Recent years have seen renewed focus on supervision as a reflective space and some indications that the tide may be turning in regard to the dominance of managerial priorities within the supervision of direct practice. It is less evident that a similar shift is taking place for supervisors themselves and, anecdotally, many describe their own supervision as having a business focus with limited scope for reflective dialogue. While the traditional functions of supervision need to adapt to fit the responsibilities of those in management positions, it remains true that these staff provide a vital containing role within the organisational hierarchy. For that to be sustained, it is important that supervisors have space and structure within which to process the emotional, intellectual and practical challenges of their work. The integration of action learning sets within post-qualifying courses for supervisors has demonstrated a useful dual function. Firstly, they provide an effective model for group supervision, facilitating in-depth reflection on complex practice issues. Secondly, they offer managers a peer supervision forum; a safe place to explore dilemmas and share the vulnerabilities which belong to management roles as well as practice.
\end{abstract}

\title{
Introduction
}

Based on the experience of using action learning sets within post-qualifying courses for managers in Scotland's social services, the paper discusses the value of this approach for social work supervisors. Over recent time there has been a renewed focus on supervision as a reflective space and awareness that managerial priorities can take precedence with detrimental consequences for direct practice. While this realisation may have helped redress the balance of functions within practitioners' supervision, it seems that supervisors' own supervision remains strongly weighted towards a business focus with limited scope for reflective dialogue. These are managers who provide a vital containing role within the organisational hierarchy. For that to be sustained, it is important that they too are supported to process the emotional, intellectual and practical challenges of their work. Action learning sets can make a useful contribution offsetting the dominant influence of managerialism and potentially serving a dual purpose for supervisors. As a model of group supervision this approach facilitates in-depth practice discussion between workers with different levels of experience or professional background. Used within peer supervision, 
action learning can offer managers a safe but challenging forum for their own practice dilemmas. This paper presents a model of action learning used within post-qualifying provision and highlights key elements which lend particular value to social work supervisors.

\section{Background context}

There is broad consensus around the functions of professional supervision with many writers adopting (or adapting) the model of administrative, educative and supportive functions (Kadushin, 1976). A fourth element, mediation, is often added in recognition of the supervisor's role as conduit between frontline practitioners and the wider organisation (Morrison, 2005). This is a two-way flow of communication facilitating the dissemination of information down through the organisational hierarchy but also ensuring that concerns are escalated up the ladder to senior management. Horizontal mediation may also be included to reflect supervisors' role as boundary spanners both within and across agencies (Conway and Monks, 2011; Williams, 2011). While the language of supervision functions has undergone review, there is more consistency than change across the literature. Hawkins and Shohet (2012) are deliberate in re-defining qualitative, developmental and resourcing functions, choosing to highlight the shared responsibilities of supervisor and supervisee. Without minimising the significance of that linguistic shift, it does not fundamentally alter the balance and interdependence of three core functions: maintaining standards, professional learning and managing the emotional impact of work in the helping professions.

There is consistency also in acknowledging that managerial priorities have increasingly dominated the agenda within supervision (Lawler, 2015; Noble and Irwin, 2009; Peach and Horner, 2007; Scottish Executive, 2006), disturbing the balance of functions and in particular, jeopardising the space for reflective dialogue and 'thoughtful' practice (Ruch, 2007a). Rather than providing an effective counterweight to 'over-reliance on proceduralised and controlling forms of practice' (Wilson, 2013, p.155), supervision has mirrored a similar preoccupation. The impact of this rational-technocratic approach has been the focus of heightened concern over recent years, demonstrated in particular within the Munro Review of Child Protection (Munro, 2011a, 2011b), but evident also in wider unease about the failure of supervision to adequately hold and contain the anxieties 
generated by direct practice (Cooper, Hetherington and Katz, 2003; Ferguson, 2011; Gibbs, 2001; Rushton and Nathan, 1996). The paradox that organisational and societal preoccupation with risk (Beck, 1992) does little to reduce the likelihood of harm occurring appears insufficient to counteract risk averse cultures which have developed in response to blame and public recrimination. It is hardly surprising then that supervision mirrors a similar conundrum where risk surveillance (Beddoe, 2010) or 'Snooper-vision' (Bartoli and Kennedy, 2015, p.144) may erode rather than support safe practice (Webb, 2006). Tolerating uncertainty (Parton, 1998; Stalker, 2003) can exact a heavy toll on practitioners and managers alike yet it is crucial for supervision 'to provide a quiet space where critical inquiry, striving for "best practice" and the risky and unpredictable aspects of human behaviour can be held in a creative tension' (Beddoe, 2010, p.1293). Cornish (2011, p.144) uses Keats' concept of negative capability to affirm the importance of being able to 'endure anxiety' rather than responding reactively.

Significant attention has been directed at the supervision of practice over recent years and in some areas increased resources committed to training supervisors. In England, following the recommendations of the Social Work Task Force (2009) an extensive training programme was delivered to first line managers in children's services, and the Assessed and Supported Year in Employment (ASYE) is linked to clear standards for supervision. Heightened interest is evidenced also in the number of journal articles published over the past five years spanning supervisory practice in diverse countries and cultures (Beddoe, Karvinen-Niinikoski, Ruch and Tsui, 2015; Bradley, Engelbrecht and Hojer, 2010; Hair, 2013; Maidment and Beddoe, 2012; O'Donoghue and Tsui, 2011, 2012). Issues of cultural competence have come to the fore with recognition that traditional western models of supervision are ill-matched to social work practice with indigenous communities and that in-depth understanding of political and social context is essential for effective supervision of frontline workers.

Interprofessional supervision (IPS) has become a priority area as the integration agenda across the UK makes it increasingly common for practitioners to have a line manager from a different professional discipline (Beddoe and Howard, 2012; Bostock, 2015; Children's Workforce Development Council, 2010; Hutchings, Cooper and O'Donoghue, 2014; Social Care Institute for Excellence, 2013). Views differ on the benefits or otherwise of 
splitting the functions of supervision (Bradley and Hojer, 2009) but there is common agreement that equal importance should be accorded to the restorative (Proctor, 1986; Wallbank, 2010) and developmental dimensions as to managerial oversight. So in theory at least, there is consensus that professional staff working in social services need space to reflect and to process the emotional impact of practice. Implicit in this is the notion of containment (Bion, 1962; Dwyer, 2007; Harvey and Henderson, 2014; Ruch, 2007b) and the idea of a holding space which enables practitioners to acknowledge and explore the feelings evoked by their work. The risks associated with blocking or denial of emotions are well documented and the damaging impact on workers, teams and organisations in addition to the implications for safe practice (Goddard and Hunt, 2011; Lees, Meyer and Rafferty, 2013; Menzies Lyth, 1988; Stokes, 1994; Whittaker, 2011). Hawkins and Shohet (2012, p.218) caution that "what the organisation does not contain, process and understand can then spill over' which makes clear that employing agencies must attend not only to the supervision of direct practice but also to supervising the supervisors.

The rich seam of writing on professional supervision grows thinner when it turns to supervisors themselves. Within a therapeutic context attention has been paid to 'containing the container' (McLoughlin, 2011; Toasland, 2007), but relatively little attention has focused on how the different functions of supervision apply to managers' own supervision. The conflicting tug between operational and strategic priorities is familiar to those in both first line and middle management roles (Hughes and Pengelly, 1997; Kearney, 2004; Patterson and George, 2014a). A report from the Chartered Institute of Personnel Development (CIPD) (2013, p.7) describes 'buffering and filtering' as part of the manager's task; a kind of boundary management which protects frontline staff from information overload but ensures that necessary communications get through. In his early writings on supervision, Morrison (1993) suggested that one factor contributing to the sidelining of the supportive function might be the relative neglect of managers' own support needs. In more senior roles, it is not uncommon for managers to make use of external consultancy supervision but the majority of supervisors in social services settings will be reliant on line management supervision. Although systematic research in this arena is limited, there is strong anecdotal evidence pointing to a primary focus on administrative/ managerial issues within the supervision offered to managers (Cousins, 2010). The 
language used is itself noteworthy with supervision in some settings re-labelled as a 'business meeting' or a 'one-to-one'. The implications of such imbalance across the core functions justify concern from various perspectives. The significance for consistent containment at personal and organisational level has already been highlighted. There may also be issues to consider in relation to the developmental aspect of supervision. A smallscale study of managers in Scotland's social services identified a tendency to prioritise the training and development needs of other staff above their own needs (Patterson and George, 2014b) but the specific gap which is being explored in this paper is the space for reflective practice.

Peer and group supervision can be used either to replace or complement the traditional model of one-to-one supervision. Both offer valuable opportunities for managers to engage with colleagues in reflection on professional issues including their supervision of others. Golia and McGovern (2015, p.639), identifying the value of peer supervision for trainee (clinical) social workers, describe how 'these encounters are trainee-led or leaderless, egalitarian-in-principle and comprise practitioners of comparable experience and expertise.' It is easy to translate the same principles to a group of managers or supervisors and to recognise how the peer relationship might offer some degree of 'holding environment' for those involved (p.645). Action learning offers a potential model for shared and critical reflection. Originating in Revans' (1980) work with frontline managers and using a formally structured process for presenting an issue and exploring it in depth, action learning sets are well suited to the professional development needs of those in supervisory roles. While first introduced in manufacturing industry, this methodology has since been applied across diverse sectors and workplaces, gaining increasing popularity within health and social services over recent years. Alongside this expansion there has also been significant divergence of approach. Action learning has a range of interpretations and it is helpful always to clarify how the term is being used. This is not to imply that rigid adherence to a single model is essential but to avoid unhelpful confusion. Within the sphere of education there has been valuable exploration of action learning as a reflective tool (McGill and Beaty, 2001; McGill and Brockbank, 2004). Burgess (1999) evaluated the use of action learning sets as part of a management development programme for social work managers and, more recently, the Scottish Social Services Council (SSSC) and NHS 
Education Scotland (NES) commissioned a three-year project to apply action learning in Health and Social Care Partnerships across Scotland (Burgess, 2014). Other publications affirm both that action learning is in vogue within social work and, more importantly, that its contribution to reflective practice is recognised (Abbott and Taylor, 2013; Ball, 2013; Skills for Care, 2014). To some extent one can distinguish between direct application of the model and adaptations such as peer consultancy which make use of action learning principles but adopt a different structure. A recent variation is the coaching circle or 'case clinic' (Scharmer, 2015) used within the U-Lab MOOC delivered by Massachusetts Institute of Technology (MIT). This approach builds on Revans' (1980) action learning methodology but introduces new dimensions including virtual circles where course participants from across the globe commit to in-depth peer support and learning.

Within an accredited post-qualifying course for supervisors in health and social services action learning has been introduced for a two-fold purpose: firstly, to provide a model of group supervision which can facilitate reflection on complex case-work and help counterbalance the managerial focus which at times dominates one-to-one supervision. Secondly, action learning is offered in response to a perceived deficit in the supervision available to supervisors themselves. While some managers have access to regular high-quality supervision and support, it is evident that many lack the opportunity for regular reflective space where assumptions can be challenged, deeper levels of thinking can occur and their own supervisory practice can be explored.

\section{Action learning methodology}

The locus for action learning which this paper describes is an accredited training course for social work supervisors. The module forms part of a Management Certificate recognised by the professional regulatory body (SSSC) as an approved award for managers of registered services. Course content is primarily focused on individual supervision but explores alternative models including peer supervision, mentoring and group supervision. One of the course tutors had previously used action learning sets as a mode of reflective supervision with a team of practitioners in a community care setting. This approach had been well received by participants and had yielded a number of benefits. It had facilitated depth of discussion around complex practice issues. In addition, it had allowed for the exchange of diverse perspectives and wide-ranging expertise from workers with different 
levels of experience and practice background. Significantly, it also provided affirmation of core values such as a non-judgemental stance, self-determination and the importance of active listening. Similar appreciation is evident in feedback from the supervision course: 'I really enjoyed opportunities to practise the skills of active listening' (course participant).

The model of action learning used on the supervision course is largely based on the process outlined by Burgess (1999) but with the key caveat highlighted to participants that any set including both supervisor and supervisees will not conform to the egalitarian principles of peer learning. When a hierarchical relationship is introduced (even when the supervisor's role is one of facilitator) it is important to mark this divergence from a more 'pure' form of action learning. The participation of a line manager brings inevitable constraints to the process and makes it unlikely that issues will be raised which relate to participants' own supervision. For that reason, it seems appropriate that group supervision using action learning is clearly focused on casework issues although an established group might choose to extend the boundaries to include team or inter-professional dynamics. By contrast, when action learning is practised as a peer activity it can encompass wide-ranging topics and work challenges.

The structure used for action learning set involves:

1. A 'bidding' process: participants are invited to bring potential issues for exploration.

2. Choosing a bid: collective decision-making on the issue to focus on in the set.

3. Presentation: the group member whose bid was chosen outlines their issue fully without interruption or questions.

4. A 'feelings' round: each group member names the emotion evoked in them by listening to the presenter.

5. A space for imagery: listeners are invited to share any mental pictures or metaphors conjured up in response to what they have heard.

6. Clarifying facts: an opportunity for questions on any relevant points.

7. Reflective discussion: the presenter leaves the immediate circle (but sits within easy hearing) while the rest of the group explore the issue together. 
8. Setting direction: the presenter re-joins the group and shares their thoughts on what they have heard and how they now intend to take things forward.

9. Process review: the whole group reflect on the action learning process as opposed to the content of the set.

The set facilitator, who in this context was also the course tutor, takes responsibility for time-keeping. Each stage of the process has a specific time allotted but this detail has not been included in the process above as the overall duration of an action learning set may vary. Generally, it will be helpful to allow at least two hours for a set but participants who are familiar with the process can discipline themselves to work effectively within a tighter time-frame.

\section{Application of action learning to the supervisory role}

\section{Active Listening}

Action learning celebrates the power of active listening. It can halt busy managers in their tracks and alert them to how rarely they fully engage in the listening process. Hales (1983) has identified the fragmented, interrupted and reactive nature of the first line manager role. Within that discontinuous flow of continuous demands, it is not simple to find a still inner space and be totally present. Maslow (1969, quoted in McGill and Brockbank, 2004, p.165) has identified how challenging it can be to 'really, wholly, passively, self-effacingly listen'. An array of obstacles get in the way of our hearing. There is a tendency to take in only part of the message and to start de-coding it and interpreting the meaning without listening through to the end. In their analysis of communication within child protection networks, Reder and Duncan (2003) distinguish between the 'sender's' understanding of the information being conveyed, and the meaning assigned by the person on the receiving end. McGill and Brockbank (2004, pp.171-3) outline different kinds of listening commonly practised: evaluative, filtered, distracted, listening with sympathy, interrupting, breaking a silence, planning a response. They describe how action learning invites participation in a 'believing game' (Elbow, 1998) where the presenter's account is received without doubt or judgement. Listening in this way, with a dispassionate and open mind, is uncommon and yet the impact of such full attentiveness is significant. 
Within an action learning set the presenter has space to be heard and also an opportunity to listen. What is evident in many instances is the atypical experience of being able to recount in detail a complex situation and reflect aloud on what is most troubling about it. A receptive listening group allows the presenter to delve deeper into their own experience without having to respond to questions. Inner thoughts are expressed and placed outside of the self where they can then be looked at with a degree of detachment. The kinds of issues brought to action learning sets are often those which provoke anxiety; concerns that intrude on one's thinking both at work and beyond work. Action learning can provide a holding space which enables the presenter to temporarily place their dilemma in the arms of the group, metaphorically speaking, and then take it up again but from a shifted position. Ball (2013, p.339) describes how these slight but significant shifts can cause 'a new direction of travel to be taken' and something of that was echoed in feedback from a course participant: 'I enjoyed the space to test out my learning in a safe and empowering environment and will take this learning back to my current post'.

\section{Problem Solving}

Action learning is grounded in a strong belief that the best solutions to complex problems will be generated by those directly involved (Revans, 1980). Rather than top-down directives, it promotes a sense of ownership on the frontline of services, using the experience and creativity of staff to respond to new challenges. The relevance of this problem-solving focus to social work practice has been noted (Abbott and Taylor, 2013) and may be one of the reasons for including action learning as part of a support programme for newly qualified social workers in England (Skills for Care, 2014). Interestingly, the experience of using action learning sets with supervisors and first-line managers in social services reveals an alternative insight. Within this process, participants are strongly encouraged to refrain from giving advice, offering solutions or believing that they know what course of action the presenter of the issue should adopt. Instead, their task is to 'bring more light to bear' upon a complex situation. They are invited to look at the problem from diverse perspectives and to use their position as detached observers to explore different, even contradictory, options. If relevant, they are encouraged to identify theoretical frameworks which may help illuminate what is playing out at individual, group or 
organisational level. The drama triangle (Karpman, 1968) often surfaces as a mode of understanding behaviour patterns which are blocking constructive progress.

It is the holding back from problem solving which seems to offer valuable learning to participants. In practising self-restraint they mirror the skills needed for supervision and are powerfully reminded that supporting staff to work out their own strategy is generally more effective than trying to 'fix' things. New supervisors can feel pressured to have all the answers but it is only with more experience that they gain confidence to acknowledge and accept uncertainty (Stoltenberg and Delworth, cited in Hawkins and Shohet, 2012). Experience of delivering supervision courses has demonstrated that established managers, as well as those new to the role, can find it hard to refrain from a problem solving response despite knowing that a facilitative management style not only supports workers' own development, but models practice which is enabling and respectful of service users' autonomy.

\section{Different Ways of Knowing}

Exploring the nature of dialogue (Bohm, 1996; Isaacs, 1999) which action learning facilitates, McGill and Brockbank (2004) highlight the significance of 'connected knowing'. This way of knowing surfaced first in Belenky, Clinchy, Goldberger and Tarule's (1986) study of the missing voices of women in adult learning and distinguishes between:

knowing - characterised by a distanced, sceptical and, impartial stance toward that which one is trying to know (a reasoning against) and connected knowing - characterised by a stance or belief and an entering into the place of the other person or the idea that one is trying to know (a reasoning with) (Goldberger et al, 1996, quoted in McGill and Brockbank, 2004, p.85).

Connected knowing engages the feelings; acknowledges heart as well as head and fundamentally affirms that deep levels of understanding depend upon relationship. As such it has direct relevance to social work practice and action learning emphasises a way of knowing which integrates thinking, feeling and action. The presenter is encouraged to identify the crux of the problem they are grappling with. This goes beyond mere facts and often highlights issues impacting on an emotional level, whether these be interpersonal 
tensions, ethical dilemmas or conflicts of interest. The first response sought from the group of listeners is feedback rooted in their emotions. They are asked to name the feeling evoked by what they have heard, without attempting to make sense of this or translate it into more articulate thoughts. For some the task is straightforward, while others stray into lengthy description and need the facilitator's encouragement to own their emotion rather than rationalise it away.

Coaching circles, or case clinics, (Scharmer, 2015) share common ground with action learning methodology. A valuable additional contribution, however, is the space for those listening to offer a further dimension of feedback to the presenter. In welcoming responses at the level of imagery, metaphor and gesture, potent information may be communicated which can lend insight where rational thinking has met an impasse: 'feelings and sensations are also used as data' (Burgess, 2005, p.2). In one set with a group of senior managers from social services, a powerful sense of urgency and imminent disaster echoed round the circle as participants brought separate images of a huge juggernaut travelling at speed on a busy motorway and an express train hurtling into the mouth of a dark tunnel. On repeated occasions, a presenter has described how their own experience is affirmed when others' responses mirror the challenge they are facing. Rather than feeling overwhelmed, it seems to quell self-doubt and bring renewed confidence that there is a way forward. Ball (2013, p.339), describing the use of action learning to create space for multi-agency reflexivity in child protection work, identifies how asking participants about feelings: 'appeared to provide a levelling of anxiety (or at least the opportunity to expose it), allowing all participants to express their fears and hopes'. It would be naïve, however, not to acknowledge that action learning can also surface negative emotions (Hillman, 2012) or may challenge the status quo in ways which provoke unease: 'sometimes learning sets are safe places where it is possible to explore feelings, and sometimes they are not' (Vince, 2004, p.65).

Supervisors in social services are involved in connected knowing; in reasoning with and alongside the staff they are working with. Relationship-based management (Ruch, 2012) models ways of knowing and ways of being which align with social work's value base and are an antidote to rational-technocratic approaches. 


\section{Structure and reflection}

Action learning is a structured and a reflective process. When used for case discussion it provides clear boundaries and promotes in-depth reflection on complex practice issues. Raelin (2006) suggests that a reflective response requires a shift from control to vulnerability and cites Bell (1998) on the necessary attributes:

- Instead of maintaining unrealistic standards, one sets realistic expectations,

- Instead of expressing trepidation, one displays tolerance,

- Instead of concentrating on self-expression, one engages in deep listening,

- Instead of being self-absorbed, one conveys humility,

- Instead of feeling out of depth, one feels open to learn,

- Instead of feeling out of context, one becomes open to experience (p.157).

The staged process of an action learning set provides a safe holding environment where it is possible to let go of fixed positions. It offers both 'feeling' and 'thinking' containment (Ruch, 2007b) allowing the presenter to stand back from the immediacy of their issue and temporarily be an onlooker. There is an initial sense of exclusion when the key player is invited to leave the circle and sit within hearing distance but out of eye contact with the rest of the group. This is not a mandatory element in action learning but experience shows that it can be liberating for all participants. The presenter moves into listening mode and is not required to answer questions, explain or defend. Those involved in exploring the issue have an open remit with the encouragement to stay open to multiple perspectives. There are no right or wrong answers but a space for trying out ideas and collective 'wondering'. Over recent years terminology has changed with traditional action learning joined by critical action learning (CAL) and critically reflective action learning (CRAL), particularly in the context of support and supervision of newly qualified social workers (Trehan and Pedler, 2010; Hillman, 2012; Skills for Care, 2014). While it is essential not to sidestep either the political dimensions of organisational life or power dynamics within practice, it can be argued that this should be integral to any version of action learning regardless of how it is labelled and in whatever context it is applied. Participants are encouraged to step back, to move from the 'battlefield' to the 'balcony' ((Benington and Hartley, 2009, p.9) and to explore issues from a range of perspectives, examining their underlying assumptions 
and those of their peers. It needs a safe learning environment to facilitate constructive challenge and open dialogue. Sometimes the timing feels wrong as indicated by one participant: 'The action learning sets felt under-utilised. I'm not sure whether this was because the first action learning set was too early in the course or whether the group wasn't going to be able to challenge each other until it was too late'. Wilson (2013) explores the contribution of social work education to reflective practice and the risk of disjunction between university and agency culture; between 'academic competence' and vocational competence' (p.168). Similar concern is expressed in the comment 'I am left wondering how useful this is as a management tool - as in the work place, it is unlikely we will have permission to use action learning sets by management and work colleagues may not trust each other enough to make them effective, compared to the anonymity of the course setting' (course participant). It is to be hoped that agencies will have the confidence to support rather than block action learning as a vehicle for critical reflection on practice. When managers use this approach as a form of peer supervision, the material they bring includes both intra- and inter-organisational challenges. A persistent tension experienced by firstline and middle managers is the opposing pull of strategic and operational priorities (Floyd and Woolridge, 1997). Having the opportunity to participate in a structured reflective process can mitigate the impact of reactive work cultures and support leadership capability which is able to navigate the political and emotional complexities of organisations.

\section{Mutuality and Learning}

A positive supervisory relationship aspires to a mutuality where both parties are open to learning from each other. This is not to ignore disparity of role and responsibility, including power imbalance, but recognises a two-way exchange where new insight can arise. This shared learning can be supported by ending each supervision session with reflective questions such as:

What have we learned that neither of us knew before?

What have we learned that we could not have learned on our own?

What new capability have we generated and what difference will that make for the people we are working with? (adapted from Hawkins and Shohet, 2012, p.239). 
In similar vein and writing about supervision, Carroll (2010, p213) believes that 'learning is as much between people as it is within people.' The parallels with action learning are evident both in terms of reciprocal relationships and commitment to new discovery. Within an action learning set, the process of choosing a bid involves consideration of different factors. The urgency or emotional content of an issue may sway the decision or participants may be influenced by how relevant the topic is to their own experience. Although a number of bids are inevitably rejected when the group settles on one, people often identify areas of commonality in the learning gained. Although it was not their issue, it carries echoes of past dilemmas or is pertinent to a current challenge: 'Working within groups, particularly Action Learning sets was very useful to reflect on and consider practice, both my own and the issues and difficulties faced by my peers' (course participant).

Within action learning there is no leading expert but a group of peers each with their own expertise. If a supervisor uses action learning as a vehicle for case discussion, their role is to facilitate and hold the space not to give direction. A key benefit, as with any form of group supervision, is the opportunity for workers with different levels of experience to participate together; for the established practice wisdom of longstanding practitioners to fuse with ideas from those still raw below the professional collar. In an integrated team it offers a forum where cross-disciplinary perspectives are brought to bear and the airing of differences brings added value. Similarly, a group of supervisors who commit to action learning as peer supervision will mirror Revans' (1980) 'comrades in adversity'; prepared to challenge as well as support each other's development. There is a kind of levelling within the process. For the duration of a set, external roles are set aside and the group's focus narrows down to the issue presented. There is a shared gaze albeit from different angles and an intensity within clear time limits. Together the participants seek to understand better and to harvest their learning both of content and process.

\section{Conclusion}

Action learning is not for everyone. It matches some people's learning style and stirs up frustration in others. There are diverse ways of reflecting on experience and one participant was polite but clear that his preferred mode is a solitary one. For some, however, group work is fertile ground for learning and this paper has looked specifically at the contribution 
action learning can make to social work supervision. Experience of integrating action learning sets within post-qualifying training for managers has demonstrated a dual benefit. The structure and principles underpinning action learning translate effectively into both group and peer supervision. Supervisors can use this approach to support critically reflective practice, bolstering the developmental and supportive functions which are sometimes squeezed within line management supervision. Furthermore, they can commit to their own professional development and reflective management practice by engaging in action learning with a group of peers. 


\section{References}

Abbott, C. \& Taylor, P. (2013). Action Learning in Social Work. London: Learning Matters, Sage.

Ball, K. (2013). Action Learning: Creating a Space for Multi-agency Reflexivity to Complement Case Management. Practice: Social Work in Action. 25, 335-347.

Bartoli, A. \& Kennedy, S. (2015). Tick If Applicable: A Critique of a National UK Social Work Supervision Policy. Practice, 27, 239-250.

Beck, U. (1992). Risk Society: Towards a New Modernity. London: Sage.

Beddoe, L. (2010). Surveillance or Reflection: Professional Supervision in 'the Risk Society'. British Journal of Social Work, 40, 1279-1296.

Beddoe, L., Karvinen-Niinikoski, S., Ruch, G. \& Tsui, M.-s. (2015). Towards an International Consensus on a Research Agenda for Social Work Supervision: Report on the First Survey of a Delphi Study. British Journal of Social Work, Advance online publication. doi:10.1093/bjsw/bcv110.

Beddoe, L. \& Howard, F. (2012). Interprofessional Supervision in Social Work and Psychology: Mandates and (Inter)Professional Relationships. The Clinical Supervisor, 31, 178-202.

Belenky, M.F., Clinchy, B.M., Goldberger, N.R. \& Tarule, J.M. (1986). Women's Way of Knowing: The Development of Self, Voice and Mind. New York: Basic Books.

Benington, J. and Hartley, J. (2009). 'Whole Systems Go!' Improving leadership across the whole public service system. National School of Government: Sunningdale Institute.

Bion, W. (1962). Learning from Experience. London: Heinemann.

Bohm, D (1996). On Dialogue. Abingdon: Routledge.

Bostock, L. (Ed.) (2015). Interprofessional Staff Supervision in Adult Health and Social Care Services. Vol. 1. Brighton: Pavilion Publishing.

Bradley, G. \& Hojer, S. (2009). Supervision Reviewed: Reflections on Two Different Social Work Models in England and Sweden. European Journal of Social Work, 12, 7185.

Bradley, G., Engelbrecht, L. \& Hojer, S. (2010). Supervision: A force for change? Three stories told. International Social Work, 53, 773-790.

Burgess, R. (1999). Reflective practice: action learning sets for managers in social work. Social Work Education, 18, 257-270. 
Burgess, R. (2014). Action learning applied in health and social care partnerships, (SSSC/NES). Retrieved from http://ifal.org.uk/wp/wp-content/uploads/2014/06/ALapplied-in-health-social-care-partnerships-Article-16May14-Robin-Burgess.pdf

Carroll, M. (2009). Supervision: Critical Reflection for Transformational Learning, Part 1.The Clinical Supervisor, 28, 210-220.

Chartered Institute of Personnel and Development (2013). Real Life Leaders: Closing the Knowing-Doing Gap. London: CIPD.

Children's Workforce Development Council (2010). Inspiring practice: A guide to developing an integrated approach to supervision in Children's Trusts. Leeds: CWDC

Conway, E. \& Monks, K. (2011). Change from below: the role of middle managers in mediating paradoxical change. Human Resource Management Journal, 21, 190-203.

Cooper, A., Hetherington, R. \& Katz, I. (2003). The Risk Factor: Making the Child Protection System Work for Children. London: Demos.

Cornish, S. (2011). Negative capability and social work: insights from Keats, Bion and business. Journal of Social Work Practice, 25, 135-148.

Cousins, C (2010). 'Treat Me Don't Beat Me' ... . Exploring Supervisory Games and Their Effect on Poor Performance Management'. Practice, 22, 281 - 292.

Dwyer, S. (2007). The emotional impact of social work practice. Journal of Social Work Practice, 21, 49-60.

Elbow, P. (1998). Writing without Teachers. (2 ${ }^{\text {nd }}$ ed.) London: Oxford University Press.

Ferguson, H. (2011). Child Protection Practice. Basingstoke: Palgrave MacMillan.

Floyd, S. W. \& Wooldridge, B. (1997.) Middle management's strategic influence and organisational performance. Journal of Management Studies, 34, 465-86.

Gibbs, J. A. (2001). Maintaining Front-Line Workers in Child Protection: A Case for Refocusing Supervision. Child Abuse Review, 10, 323-335.

Goddard, C. and Hunt, S. (2011) The complexities of caring for child protection workers: the contexts of practice and supervision, Journal of Social Work Practice, 25, 413-432

Golia, G.M. \& McGovern, A.R. (2015). If You Save Me, I'll Save You: The Power of Peer Supervision in Clinical Training and Professional Development. British Journal of Social Work, 45, 634-650.

Hales, C. (1993). Managing through Organisation. London: Routledge. 
Hair, H. (2013). The Purpose and Duration of Supervision, and the Training and Discipline of Supervisors: What Social Workers Say They Need to Provide Effective Services. British Journal of Social Work, 43, 1562-1588.

Harvey, A \& Henderson, F. (2014). Reflective Supervision for Child Protection Practice Reaching Beneath the Surface. Journal of Social Work Practice, 28, 343-356.

Hawkins, P. \& Shohet, R. (2012). Supervision in the Helping Professions (4th ed.). Maidenhead: Open University Press.

Hughes, L. and Pengelly, P. (1997). Staff Supervision in a Turbulent Environment: Managing Process and Task in Frontline Services. London: Jessica Kingsley.

Hillman, A (2012). Working with negative emotions in sets. Action Learning: Research and Practice, 9, 177-182.

Hutchings, J., Cooper, L. \& O’Donoghue, K. (2014). Cross-disciplinary supervision amongst social workers in Aotearoa New Zealand. Aotearoa New Zealand Social Work, 26, 53-64.

Isaacs, W (1999). Dialogue and the Art of Thinking Together: a pioneer approach to communicating in business and in life. New York, NY: Doubleday.

Kadushin, A. (1976). Supervision in Social Work. New York, NY: Columbia University Press.

Karpman, S. (1968). 'Fairy tales and script drama analysis. Transactional Analysis Bulletin, 7(26), 39-43.

Kearney, P. (2004). First Line Managers: The Mediators of Standards and the Quality of Practice. In D. Statham, (Ed.), Managing Front Line Practice in Social Care (pp.103-116). London: Jessica Kingsley.

Lawler, J. (2015). Motivation and Meaning: The Role of Supervision. Practice, 27, 265275

Lees, A.; Meyer, E. \& Rafferty, J. (2013). From Menzies Lyth to Munro: The Problem of Managerialism. British Journal of Social Work, 43, 542-558.

McGill, I. \& Beaty, L. (2001). Action Learning: A Guide for Professional, Management and Educational Development ( $2^{\text {nd }}$ ed.). London: Kogan Page.

McGill, I. \& Brockbank, A. (2004). The Action Learning Handbook. Abingdon: Routledge.

McLoughlin, C. (2010). Concentric circles of containment: a psychodynamic contribution to working in pupil referral units. Journal of Child Psychotherapy, 36, 225-239. 
Maidment, J. \& Beddoe, L. (2012). Is Social Work Supervision in "Good Heart"? A Critical Commentary. Australian Social Work, 65, 163-170.

Menzies-Lyth, I. (1988). Containing Anxiety in Institutions: Selected Essays, Volume One. London: Free Association Books.

Morrison, T. (1993). Staff Supervision in Social Care: An Action Learning Approach. London: Longman.

Morrison, T. (2005). Staff Supervision in Social Care: Making a Real Difference for Staff and Service Users (3rd ed.). Brighton: Pavilion.

Munro, E. (2011a). The Munro Review of Child Protection Interim Report: The Child's Journey. Retrieved from: https://www.gov.uk/government/publications/munro-reviewofchild-protection-interim-report-the-childs-journey .

Munro, E. (2011b). The Munro Review of Child Protection: Final Report - A ChildCentred System, The Stationery Office, London. Retrieved from: https://www.gov.uk/government/publications/munro-review-of-child-protection-finalreport-a-child-centred-system .

Noble, C. \& Irwin, J. (2009). Social Work Supervision: An Exploration of the Current Challenges in a Rapidly Changing Social, Economic and Political Environment. Journal of Social Work, 9, 345-358.

O'Donoghue, K. \& Tsui, M.-s. (2011). Towards a professional supervision culture: The development of social work supervision in Aotearoa New Zealand. International Social Work, 55, 5-28.

O'Donoghue, K. \& Tsui, M.-s. (2012). In Search of an Informed Supervisory Practice: An Exploratory Study. Practice: Social Work in Action, 24, 3-20.

Parton, N. (1998). Risk, advanced liberalism and child welfare: The need to rediscover uncertainty and ambiguity. British Journal of Social Work, 28, 5-27.

Patterson, F. \& George, C. (2014a). Scoping Analysis on the Role and Functions of Middle Managers in Social Services. Dundee, SSSC. Retrieved from: http://www.sssc.uk.com/about-the-sssc/multimedialibrary/publications?task=document.viewdoc\&id=1476

Patterson, F. \& George, C. (2014b). Middle Managers in Scotland's Social Services: Leadership Learning Needs. Dundee, SSSC (internal publication).

Peach, J. \& Horner, N. (2007) Using supervision: support or surveillance. In M. Lymbery and K. Postle (Eds.). Social Work: A Companion to Learning, London: Sage. 
Proctor, B. (1991). Supervision: A co-operative exercise in accountability. In M. Marken \& M. Payne (Eds.), Supervision in Practice. (pp.21-23). Leicester: National Youth Bureau and Council for Education and Training in Youth and Community Work.

Raelin, J. (2006). Does Action Learning Promote Collaborative Leadership? Academy of Management Learning and Education, 5, 152-168.

Reder, P. \& Duncan, S. (2003). Understanding Communication in Child Protection Networks. Child Abuse Review, 12, 82-100.

Revans, R. (1980). Action learning: New techniques for management. London: Blond \& Briggs Ltd.

Ruch, G. (2007a). 'Thoughtful' practice: child care social work and the role of case discussion. Child and Family Social Work, 12, 370-379.

Ruch, G. (2007b). Reflective Practice in Contemporary Child-care Social Work: The Role of Containment. British Journal of Social Work, 37, 659-680.

Ruch, G. (2012). Where Have All the Feelings Gone? Developing Reflective and Relationship-Based Management in Child-Care Social Work. British Journal of Social Work, 42, 1315-1332.

Rushton, A. \& Nathan, J. (1996). The Supervision of Child Protection Work. British Journal of Social Work, 26, 357-374.

Scharmer, O. (2015). Transforming Business, Society and Self with U.Lab, Massachusetts Institute of Technology MOOC, Retrieved from: https://courses.edx.org/courses/coursev1:MITx+15.671x+3T2015/info

Social Care Institute for Excellence (2013). Practice enquiry into supervision in a variety of adult care settings where there are health and social care practitioners working together. London: SCIE.

Scottish Executive (2006). Changing Lives: The 21st Century Social Work Review. Edinburgh: Scottish Executive.

Social Work Task Force (2009). Building a Safe, Confident Future: The Final Report of the Social Work Task Force. Department for Education.

Skills for Care (2014). Critically reflective action learning: Improving social work practice through critically reflective action learning. Leeds: Skills for Care.

Stalker, K. (2003). Managing risk and uncertainty in social work: A literature review. Journal of Social Work, 3, 211-33.

Stokes, J. (1994). Institutional chaos and personal stress. In A. Obholzer \& V. 
Zagier-Roberts (Eds.), The Unconscious at Work: Individual and Organisational Stress in the Human Services. Routledge: London.

Toasland, J. (2007). Containing the container: an exploration of the containing role of management in a social work context. Journal of Social Work Practice, 21, 197-202.

Trehan, K. \& Pedler, M. (2010). Critical Action Learning. In J. Gold, R. Thorpe \& A. Mumford (Eds.), Gower Handbook of Management Development, (5 ${ }^{\text {th }}$ ed.) Farnham: Gower.

Vince, R. (2004). Action learning and organizational learning: power, politics and emotion in organizations. Action Learning: Research and Practice, 1, 63-78.

Wallbank, S. (2010). Effectiveness of individual clinical supervision for midwives and doctors in stress reduction: findings from a pilot study. Evidence-Based Midwifery, 8, 2834.

Webb, S. A. (2006). Social Work in a Risk Society: Social and Political Perspectives. New York, NY: Palgrave Macmillan.

Whittaker, A. (2011). Social defences and organisational culture in a local authority child protection setting: challenges for the Munro Review? Journal of Social Work Practice, 25, 481-495.

Williams, P. (2011). The Life and Times of the Boundary Spanner. Journal of Integrated Care, 19(3), 26-33.

Wilson, G. (2013). Evidencing Reflective Practice in Social Work Education: Theoretical Uncertainties and Practical Challenges. British Journal of Social Work, 43, 154-172. 